\title{
Colorectal cancer screening in asymptomatic populations
}

\author{
A R Hart, A C B Wicks, J F Mayberry
}

\begin{abstract}
Colorectal cancer is the second commonest cause of cancer death in the UK. An effective national screening programme is urgently required to reduce the substantial morbidity and mortality from the disease. The success of any screening programme will depend on the screening test detecting early Dukes's A carcinomas and adenomatous polyps. Prognosis is directly related to tumour staging and a proportion of carcinomas are thought to arise from polyps. Two screening methods exist - faecal occult blood testing and sigmoidoscopy. Large trials of faecal occult blood testing show that it detects more early lesions than in patients presenting with symptoms, but whether this reduces mortality is not yet confirmed and lack of sensitivity for cancers and polyps may ultimately limits its usefulness. The role of sigmoidoscopy in screening, particularly flexible sigmoidoscopy, has not been fully investigated. Flexible sigmoidoscopy has a greater sensitivity for distal lesions than stool testing and a randomised controlled trial of its efficacy is planned in Britain. Compliance with screening is essential to ensure its cost effectiveness in both health and economic terms. Large trials of faecal occult blood testing conducted over several years achieved compliance rates in excess of $60 \%$, although in smaller studies these are often much less. Women frequently participate more than men. There are many reasons for noncompliance including lack of appreciation of the concept of asymptomatic illness and fear of the screening tests and cancer itself. Colorectal cancer screening is relatively cheap compared with breast and cervical cancer screening. Provisional cost estimates suggest that the amount spent to detect or prevent cancer by screening is similar to the amount required to treat a symptomatic patient. (Gut 1995; 36: 590-598)
\end{abstract}

Keywords: colorectal cancer, screening, faecal occult blood testing, sigmoidoscopy.

Research Unit, Leicester General Hospital, Leicester A R Hart

A C B Wicks

J F Mayberry

Correspondence to: Dr A R Hart,

Gastroenterology Research

Unit, Leicester General

Hospital, Gwendolen Road,

Leicester LE5 4PW

Accepted for publication

29 July 1994 criteriang to be effective flve criteria must be met. Firstly, the disease question should be an important public health problem causing substantial morbidity and mortality. Colorectal cancer is the second commonest cause of cancer death in Britain, with a similar high mortality in the USA of
57000 annual fatalities. The second criterion is that the disease's natural history should be compatible with early detection at a premalignant or asymptomatic stage. Colorectal cancers are thought to arise from benign adenomas so screening must detect these premalignant lesions. Screening must also diagnose cancer at an early stage as prognosis is related to Dukes's staging. Thirdly, the screening test must be sensitive, safe, and exclude those who do not have the disease. The current methods used in colorectal cancer screening programmes are stool tests to detect occult blood from tumours and sigmoidoscopy to visualise distal lesions. The fourth criterion is high compliance with the screening test. Compliance with screening is related to the method of delivery. A thorough understanding of why people fail to participate is critical to increase uptake in future programmes. Finally, the cost of screening must be comparable to the money saved by preventing the disease. This review discusses whether these criteria are met in colorectal cancer screening and compares current knowledge with what is known in cervical and breast cancer screening.

Criterion 1: Colorectal cancer is a significant public health problem

There are 25000 annual colorectal cancer registrations in England and Wales and a further 3000 in Scotland. Over 19000 people die from the disease each year in Britain making it the second commonest cause of death from malignancy. Similarly, in the United States there are 152000 new registrations and 57000 deaths from the disease. Five year survival is related to tumour staging and despite advances in surgery and chemotherapy it is still poor at $30 \%$ to $53 \%$. Those patients with a lesion confined to the bowel wall (Dukes's A) have a survival of $82 \%$ to $87 \%$ compared with only $7 \%$ to $13 \%$ for patients with metastatic disease. In a specialist colorectal surgical unit, five year survival was $57 \%$ in a series of over 3000 patients with rectal carcinoma. ${ }^{1}$ In the north east of Scotland, which has the highest recorded rates of the disease in Britain, half the patients were found to be potentially curable at laparotomy, and half of these were alive without recurrence seven years later. $^{2}$

Treating patients with colorectal cancer is expensive. Each year the NHS spends at least £100 million treating inpatients with the disease at a cost of $£ 4500$ per patient. A cost effective national colorectal cancer screening programme is urgently required to detect 
asymptomatic lesions and reduce the significant morbidity and mortality of this disease.

\section{Criterion 2: The natural history is compatible with early detection at a premalignant or early cancer stage}

Colorectal cancer is ideally suited to a screening programme as malignant neoplasms are thought to arise from benign adenomatous polyps.

\section{POLYPS AND THE ADENOMA-CARCINOMA SEQUENCE}

Approximately two thirds of patients have a single adenoma and these are usually in the rectosigmoid region. ${ }^{3-5}$ Between $27 \%$ and $71 \%$ are larger than $1 \mathrm{~cm}$, and a quarter to one third have either tubulovillous or villous histology. Five to $11 \%$ of polyps contained invasive carcinoma and an even higher proportion had carcinoma in situ.

Evidence that adenomas undergo malignant transformation comes from histological, ${ }^{46}$ radiological, ${ }^{7}$ and genetic studies. Polyps often contain foci of neoplastic cells and it would seem reasonable to assume malignant spread occurs. In 2500 polyps reported from St Mark's Hospital, London ${ }^{4}$ only $1 \%$ of polyps less than $1 \mathrm{~cm}$ in diameter contained malignant cells but this increased to $46 \%$ for those greater than $2 \mathrm{~cm}$. Polyps containing villous adenomatous tissue and severe dysplasia are more likely to harbour malignant cells. The American national polyp study ${ }^{5}$ analysed polyp characteristics in patients referred for colonoscopy. In total 2362 patients had 5066 polyps, $67 \%$ of which were adenomas, $11 \%$ hyperplastic, and the rest were classified as 'other', for example, juvenile polyps. Of the adenomas removed, $6 \%$ had either severe dysplasia or carcinoma in situ. This study 5 showed a reduction in the expected incidence of colorectal cancer through the practice of polypectomy and follow up colonoscopy. ${ }^{8}$ The incidence of colorectal cancer was compared with that in two cohorts ${ }^{79}$ in whom polyps were not removed and a general population registry. Only five asymptomatic early colorectal cancers (malignant polyps) were detected by follow up colonoscopy compared with an expected number of 48,43 , and 21 polyps in the three reference groups, representing a reduction in incidence of at least $76 \%$. Although the study is not a randomised trial of polyp removal it is the best available evidence that polypectomy is beneficial. Clearly a randomised trial would be both impractical and unethical.

The adenoma-carcinoma sequence is supported by genetic studies showing in vitro transformation of benign cell lines to malignant cells. This occurs when exogenous carcinogens are applied and is accompanied by a decreased response to inhibitory growth factors. Abnormalities in multiple tumour suppressor genes in chromosome 18 are partly responsible for malignant transformation and progression of colorectal cancer. Radiological data ${ }^{7}$ showed that $8 \%$ of polyps became malignant over 10 years, and $24 \%$ at 20 years. Finally, in a small study of four patients with rectal polyps who refused polypectomy, three developed malignancies. ${ }^{6}$

Interrupting the adenoma-carcinoma sequence fulfils the screening criteria that early asymptomatic disease can be diagnosed and easily treated. This concept also exists in screening for cervical carcinoma where early asymptomatic benign lesions are sought. The natural history of cervical carcinoma shows that like colonic cancer, both presymptomatic dysplastic cervical lesions and carcinoma in situ become malignant. As with colonic polyps, cervical carcinoma in situ takes an average 10 to 12 years to become invasive. Approximately $13 \%$ to $70 \%$ of untreated non-invasive cervical cancers become invasive after 12 years. In mammographic screening, although precancerous lesions are not detected, cancers are diagnosed at an earlier stage than in controls.

\section{Criterion 3: Screening tests must be sensitive, safe, and specific}

The two methods of screening for colorectal cancer and polyps are examining stool samples for occult blood and sigmoidoscopic examination of the rectum and distal colon.

THE NATURE OF FAECAL OCCULT BLOOD TESTS Detection of asymptomatic colorectal cancer by faecal occult blood testing was developed by Greegor in 1967. This method specifically identifies blood from the colon, whereas blood from upper gastrointestinal sources has a minimal effect. Tests may be falsely positive in the presence of animal haemoglobin from red meat or vegetable peroxidases, but high fibre has no effect. The positive rate may be reduced by threequarters in healthy volunteers who avoid red meat. Similarly, when foods with a high peroxidase content, such as cauliflower, cucumber, grapefruit, and carrot are omitted from the diet the positive rate falls by $85 \%$. In screening programmes, dietary retesting of positive individuals on a modified diet more than halved the initial rate and reduced those needing colonoscopy. ${ }^{10}$ Such a policy missed a cancer in one in 80 people.

Drugs can influence the results and vitamin C preparations, aspirin, and non-steroidal anti-inflammatory drugs (NSAIDs) should be avoided. Although iron is probably acceptable, the staining of stools makes smears more difficult to read. Vitamin $\mathrm{C}$ causes false negative results by inhibiting peroxidases in haemoglobin. Although aspirin and NSAIDs cause upper digestive tract bleeding as blood passes through the gut, pseudo-peroxidase activity of haem is decreased, reducing the chances of a positive test. In practice, the blood loss due to NSAIDs is similar to controls.

SENSITIVITY OF FAECAL OCCULT BLOOD TESTS The proportion of guaiac tests that are positive is related to the quantity of gastrointestinal 
TABLE I Results of controlled trials in colorectal cancer screening

\begin{tabular}{llllll}
\hline & $\begin{array}{l}\text { Trial } \\
\text { size }\end{array}$ & $\begin{array}{l}\text { Test } \\
\text { positive } \\
(\%)\end{array}$ & $\begin{array}{l}\text { Compliance } \\
(\%)\end{array}$ & $\begin{array}{l}\text { Dukes's } \\
\text { A test } \\
\text { group } \\
\text { (\%) }\end{array}$ & $\begin{array}{l}\text { Cancer } \\
\text { control } \\
\text { group } \\
\text { (\%) }\end{array}$ \\
\hline Notringham, England & 142690 & $2 \cdot 1$ & $53 \cdot 8$ & 30 & 13 \\
Minnesota, USA & 46551 & $9 \cdot 8$ & $75 \cdot 2$ & 30 & 22 \\
Goteborg, Sweden & 51325 & $6 \cdot 0$ & $65 \cdot 0$ & 30 & 12 \\
Funen, Denmark & 30970 & $1 \cdot 0$ & $67 \cdot 0$ & 27 & 9 \\
New York, USA & 22000 & $3 \cdot 7$ & $74 \cdot 0$ & $65^{\star}$ & 33 \\
\hline
\end{tabular}

The test group is composed of those completing kits, patients presenting with interval cancers, and non-responders. If the later two groups are excluded the proportion of Dukes's A cancers is higher. ^Dukes's A and B tumours.

blood loss. Normal gastrointestinal loss is between 0.5 and $2 \mathrm{ml} / \mathrm{d}$ and this amount can cause guaiac tests to be positive. A physiological blood loss of $2 \mathrm{ml} / \mathrm{d}$ will cause a guaiac test to be positive $7 \%$ of the time. For a blood loss of $10-20 \mathrm{ml} / \mathrm{d}, 61 \%$ of slides are positive, but this increases to $93 \%$ for $30 \mathrm{ml} / \mathrm{d}$. As tumours bleed intermittently and in variable amounts, collection over three days is recommended. In patients with colorectal carcinoma, sensitivity from three stool collections ranges from 53\% to $82 \%$. Sensitivity for polyps is lower at $19 \%$ to $45 \%$, although this increases with multiple adenomas, larger polyps, and left sided lesions.

Test sensitivity is improved by slide rehydration before the addition of developer solution. A possible need for slide rehydration arose from concern that drying of slides during storage may cause false negative results. Although rehydration increases sensitivity, specificity decreases. In a study of 205 cancers, adding water to slides raised sensitivity from $81 \%$ to $93 \%$, but specificity fell from $98 \%$ to $90 \% .{ }^{14}$ Rehydration unfortunately increases the number of false positives tests and leads to many unnecessary colonoscopies.

Guaiac stool tests are ideal for a screening programme as they are safe and inexpensive. Ultimately their usefulness may be limited by lack of sensitivity for polyps and their inability to exclude everyone without disease. To improve diagnostic accuracy new faecal occult blood tests are under development. These include immunological tests which use antibodies directed against the globin of human haemoglobin and haem-porphyrin tests which measure stool haemoglobin.

Lack of sensitivity and specificity are not unique to colorectal cancer screening. Initial mammographic breast screening had a specificity of $94 \%$, although only $1 \%$ of women required a biopsy to establish that the lesion was not malignant. Unfortunately interval breast cancers do occur at a rate of 1.4 per 1000 screened in Britain. This is comparable to the British colorectal cancer screening

TABLE II Polyps detected by screening

\begin{tabular}{|c|c|c|c|c|}
\hline \multirow[b]{2}{*}{ Centre } & \multicolumn{2}{|c|}{ Patients with adenomas $/ 10^{4}$} & \multirow{2}{*}{$\begin{array}{l}\text { Polyps } \\
>1 \mathrm{~cm} \\
(\%)\end{array}$} & \multirow{2}{*}{$\begin{array}{l}\text { Villous or } \\
\text { tubulovillous histology } \\
\text { (\% polyps) }\end{array}$} \\
\hline & $\begin{array}{l}\text { Screened } \\
\text { group }\end{array}$ & $\begin{array}{l}\text { Control } \\
\text { group }\end{array}$ & & \\
\hline $\begin{array}{l}\text { Nottingham } \\
\text { Denmark } \\
\text { Sweden }\end{array}$ & $\begin{array}{l}8 \cdot 3 \\
4 \cdot 2 \\
9 \cdot 5\end{array}$ & $\begin{array}{l}1 \cdot 1 \\
1 \cdot 2 \\
1 \cdot 6\end{array}$ & $\begin{array}{l}64 \\
79 \\
55\end{array}$ & $\begin{array}{r}38 \\
17 \\
-\end{array}$ \\
\hline
\end{tabular}

The polyp incidence shown for all three centres is that detected at the initial screen. For Denmark and Sweden, the polyp characteristics are those found at the first screen. The polyp characteristics for Nottingham represent those found at screening and rescreening. programme where approximately one in every 800 subjects with a negative test presented with an interval carcinoma. ${ }^{16}$ Test sensitivity is a problem in cervical screening. A screening frequency of one year will reduce the calculated cumulative rate of invasive cervical cancer by $93 \%$, whereas a screening frequency of five years gives a reduction of $84 \%$. With cervical cancer there are also borderline smears - that is, ones with minor nuclear abnormalities. The number of such smears can be as high as $4 \%$ with $22 \%$ of these patients developing true positive smears over a nine year period.

\section{CANCERS DETECTED BY FAECAL OCCULT} BLOOD TESTS

There are five large controlled trials of faecal occult blood testing in Europe 15162021 and the United States ${ }^{17} 18$ (Table I). Compliance was highest in Minnesota ${ }^{17}$ and New York, ${ }^{19}$ where volunteers and those already participating in health prevention schemes were enrolled. Although uptake was lower in Nottingham, acceptance rose to over $60 \%$ during the study. ${ }^{16}$ The variation in test positive rates between trials is related to slide preparation: centres that rehydrated slides had the highest figures. ${ }^{1721}$ All trials showed favourable staging of tumours in those screened compared with patients with symptoms. In Nottingham ${ }^{1516}$ there were four times as many Dukes's A cancers in the screened group $(52 \% v 13 \%$, $\mathrm{p}<0.001$ ), with a similar ratio in Sweden ${ }^{21}$ $(50 \%$ v $12 \%, \mathrm{p}<0.01)$. In Nottingham the proportion of stage $\mathrm{D}$ cancers was lower in those screened ( $5 \% v 22 \%, \mathrm{p}<0.001)$. The Danish study also confirmed this earlier staging of tumours detected during screening. ${ }^{20}$ The Minnesota project reported the cumulative incidence of Dukes's A lesions was higher in those screened annually than controls, and the incidence of metastatic disease was nearly halved. ${ }^{17}$ The New York study, was a trial of rigid sigmoidoscopy versus rigid sigmoidoscopy plus faecal occult blood testing in 21756 people enrolled in a preventive medicine programme. ${ }^{1819}$ Sixty nine per cent of subjects undergoing their first health check had a Dukes's A or B tumour or a malignant adenoma compared with only $35 \%$ in the control group that was not offered stool testing. The study is limited because it recruited health conscious individuals enrolling for medical checks, there were differences between test and control group population size and characteristics, and a proportion of subjects had symptoms.

These trials also show that screen detected cancers are more amenable to treatment by endoscopic polypectomy, fewer emergency procedures are needed, ${ }^{15}$ and patients spend less time in hospital with fewer postoperative complications.

Other screening programmes in progress include a controlled trial of 94000 people in Burgundy, France and a case-control evaluation in the former West Germany. ${ }^{22}$ The provisional results from the French trial show a compliance of $52 \%$ with a cancer diagnosed in 
one in every thousand subjects completing the test, half of which were Dukes's A lesions. The results from this German case-control study ${ }^{22}$ are discussed in the next section.

DOES FAECAL OCCULT BLOOD TESTING REDUCE MORTALITY?

The crucial question is whether early detection of disease reduces mortality. Screening may just detect cancer earlier in those who are going to succumb to the disease anyway (lead-time bias) or detect slow growing, well differentiated tumours with a good prognosis (length bias). This length bias has been reported ${ }^{15}$ where more screen detected cancers $(90 \%)$ were well or moderately differentiated compared with controls $(70 \%)$. The Minnesota study is the first to report a significant mortality reduction with annual faecal occult blood testing, ${ }^{17}$ but not in those tested once every two years. In the annually screened group the 13 year cumulative mortality fell by $33 \%$. This result must be interpreted cautiously as nearly $10 \%$ of slides were positive and $38 \%$ of participants had at least one colonoscopy. Reduction in deaths may be due to cancers and polyps detected by colonoscopy rather than as a benefit of stool testing. The New York ${ }^{19}$ study reported a $43 \%$ reduction in mortality from colorectal cancer, although this just failed to reach statistical significance $(p=0.053$, one sided). Provisional results from the first five years of the Danish programme did not show a mortality reduction with two yearly screening. The full results of the European trials of faecal occult blood testing should be available in several years.

A case-control study from population based screening in Saarland, Germany showed a benefit from faecal occult blood testing in women but not in men. ${ }^{22}$ Faecal occult blood testing is offered as an optional component of the insurance system in Germany. For three years before diagnosis, $13 \%$ of male subjects and $14 \%$ of male controls had at least one symptomatic faecal occult blood test. For women, $16 \%$ of subjects had been screened and $29 \%$ of controls. Clearly many selection biases exist and these results must be interpreted as supportive of the benefits of screening.

Despite the need for clinical trials to show the benefits of screening, this only exists for breast cancer. Mammographic screening for breast cancer reduces mortality by $30 \%$, although this is confined to women over the age of 50 years. The non-randomised UK trial showed a reduction in mortality of $20 \%$, although this just failed to reach significance. There is no randomised trial of cervical screening, but supportive evidence comes from a comparison of screened and unscreened groups and correlations between mortality reduction and intensity of screening. For example, time trends in mortality from cervical cancer have been compared in Nordic countries and correlated with the intensity of screening programmes. In Iceland, where the nationwide programme had the widest target age range, the fall in mortality was greatest at $80 \%$.

THE PROBLEM OF 'MISSED' CANCERS

Missed cancers give screening programmes a poor reputation. The interval cancer rate is the number presenting between a negative test and rescreening divided by the total number of cancers diagnosed. This rate assumes missed tumours were present at the time of testing, although this may not be so. In Nottingham and Denmark there were interval cancer rates of $28 \%$ and $48 \%$ respectively. ${ }^{16} 20$ The positive rate for faecal occult blood tests in Britain was double that of Denmark and this contributed to fewer interval cancers. In Sweden, approximately a third of cancers were missed with a screening interval of 15 to 20 months. ${ }^{21}$

Missed cancers occur in mammographic screening and are related to the age of women participants. For example, the ratio of screen detected to interval cancers was about $1: 1$ for women younger than 50 years and 3:1 for older women during a two year screening interval. ${ }^{24}$ The problem of interval cancers with smear testing was discussed earlier where nearly one in five of women with cervical cancer had a negative smear within five years. ${ }^{25}$

In summary, faecal occult blood testing meets several screening criteria in that the disease is identified earlier in its natural history and screening diagnoses more tumours with a better prognosis. The current available evidence gives conflicting opinions on whether mortality is reduced, although European trials have yet to report their mortality figures.

\section{MATHEMATICAL MODEL OF SCREENING} SIGMOIDOSCOPY

Sigmoidoscopy is more sensitive than faecal occult blood testing for distal tumours and polyps as these can be directly visualised. However, there is no controlled clinical trial showing a benefit from either rigid or flexible sigmoidoscopy in preventing cancer or improving prognosis. Despite this The American Cancer Society suggests annual faecal occult blood testing and flexible sigmoidoscopy every three to five years from the age of 50 . This recommendation is based on a mathematical model $^{26}$ derived from clinicians' opinions on the disease's history and treatment outcomes. A yearly faecal occult blood test and a flexible sigmoidoscopy once every three years reduced the probability of a male aged 50 to 75 years dying from colorectal cancer by $36 \% .^{26}$ Although organisations such as the American Gastroenterological Association and the World Health Organisation Collaborating Center for the Prevention of Colorectal Cancer promote screening sigmoidoscopy in conjunction with occult blood testing, neither the Canadian Task Force on Periodic Health Examinations nor The United States Preventive Services Task Force recommend it in individuals at average risk.

Much of sigmoidoscopy's value is thought due to the protective effect of the first 
sigmoidoscopy which diagnoses and removes polyps ${ }^{27}$ and enters people into colonic surveillance programmes. Atkin et $a^{27}$ argued that such a programme could prevent 5500 colorectal cancer cases and 3500 deaths in the UK each year, but this is dependent on a compliance of $65 \%$.

\section{UNCONTROLLED TRIALS OF SIGMOIDOSCOPY}

In an uncontrolled study in 21000 people, 113800 rigid sigmoidoscopies were performed together with polypectomy where indicated. ${ }^{28}$ Twenty seven cancers were found on initial examination - that is, one in every 800 people screened. The follow up period was of over 100000 patient years experience. Only 13 rectal cancers developed compared with an expected 90 and the authors concluded that distal polyp removal led to an $85 \%$ reduction in incidence of rectal cancer. The five year survival rate of $64 \%$ was twice that reported for people who present with colonic symptoms. There were 27 cancers detected at the initial screening examination. If these were added to the 13 detected by follow up examination, the risk of cancer was reduced by only a half. Supportive evidence of screening sigmoidoscopy came from a follow up study of 1600 patients who had adenomas removed at rigid sigmoidoscopy. ${ }^{9}$ Only $0.9 \%$ of patients developed rectal cancer compared with an estimated $5 \%$ to $10 \%$ over 14 years of follow up.

In 1964, the Kaiser Permanente Health Care Program began a randomised trial of rigid sigmoidoscopy in California. ${ }^{29}$ Altogether 5156 members were offered annual. sigmoidoscopy, and mortality from colorectal cancer was compared with that in 5557 controls not offered screening. Over a 16 year period, the number of colorectal cancer deaths in the control group was more than twice that in the study population. The authors subsequently questioned the value of the programme as at least $30 \%$ of the study group and $25 \%$ of the control group were exposed to at least one sigmoidoscopy with similar polyp removal rates. The reduction in mortality in this small trial may have been due to a lower than expected incidence and improved staging of cancer in those screened. Selby et $a l^{30}$ used Kaiser Permanente data for a retrospective case control study. Exposure to rigid proctosigmoidoscopy 10 years before death in 261 cases of colorectal cancer was compared with 868 control subjects. Only $9 \%$ of cancer patients had undergone proctosigmoidoscopy and polypectomy compared with $25 \%$ of controls, suggesting a $70 \%$ reduction in risk because of the procedure. In a smaller case-control analysis, exposure to predominantly flexible sigmoidoscopy was associated with a reduction in cancer incidence of $80 \%{ }^{31} \mathrm{Hertz}^{32}$ reported the results of rigid examination in 26000 patients, nearly half of whom had some colonic symptoms. Carcinoma was diagnosed in one in 450 examinees and $81 \%$ of cancers were Dukes's A or B. Data on 50 of these patients at five years revealed a survival rate of $88 \%$. In this study only $60 \%$ of tumours were actually seen at proctosigmoidoscopy, the others were found on barium enema requested because of bleeding or other symptoms.

The available evidence shows that flexible sigmoidoscopy is an acceptable investigation. In a study in Ireland, the compliance rate was $68 \%{ }^{33}$ and in a programme in Norway total attendance was $81 \% .{ }^{34}$ The detection rate for adenomatous polyps ranges from $6 \%$ to $35 \%$ and a carcinoma is found in one in every 200 individuals screened. ${ }^{33} 34$

\section{Criterion 4: Achieving a high compliance is essential}

\section{ACCEPTANCE OF SCREENING}

In the published trials compliance has been highest in the USA (Table I) where volunteers from the American Cancer Society ${ }^{17}$ and those in private health schemes were recruited. ${ }^{18}$ European studies are community based programmes and in Scandinavia ${ }^{2021}$ compliance reached $65 \%$. In Nottingham compliance rose from an initial $45 \%$ to $60 \%$ in the most recently recruited practices. ${ }^{16}$ Compliance is generally better in women aged 50 to 60 years.

Smaller studies from general practice confirm this sex and age difference. In Frome, Somerset, overall compliance was only $27 \%$, and in both sexes compliance was least in those over 70 years old. Similarly in Salford, Manchester, overall participation was $28 \%$ with more 40 to 49 year olds completing kits $(31 \%)$ than those over $70(17 \%)$. In Surrey, the compliance rate was $42 \%$, and again more young women participated. However, there is still a long way to go to achieve uptake comparable to the $60 \%$ seen in British trials of mammography.

The effect of social class on the uptake of stool testing is uncertain. Farrands et al ${ }^{35}$ found acceptance lowest in social classes 3 and 4. In contrast, Dent and Goulston ${ }^{36}$ reported that blue collar workers said they were more likely to participate $(78 \%)$ than white collar staff $(65 \%)$. In mammography and smear testing it is least in lower social classes.

\section{METHODS OF DELIVERING AND PROMOTING} SCREENING

The method of delivery affects compliance with screening. A letter of invitation from a family doctor was more effective than a similar letter from a university department of community medicine. ${ }^{37}$ Hobbs et al ${ }^{38}$ offered people a Haemoccult test at routine general practice consultations. Although $56 \%$ of those offered a test completed it, only $26 \%$ of the target population were screened within two years. Similarly, in Farnborough and Basingstoke when kits were offered directly to patients at routine consultations, uptake was $57 \%{ }^{39}$ Mant et al ${ }^{40}$ offered faecal occult blood testing with a free health check but found this did not raise compliance.

The value of health education is uncertain. Hardcastle et al $^{37}$ found an educational letter sent two weeks before the test invitation raised 
TABLE III Approaches which increase compliance in colorectal cancer screening

\begin{tabular}{llll}
\hline & \multicolumn{3}{l}{ Compliance (\%) } \\
\cline { 2 - 4 } Approach & Control & Test & Ref no \\
\hline Letter from GP rather than from community health department & 26 & 38 & 37 \\
Pre-invitation educational letter & 38 & 47 & 37 \\
Pre-invitation interview & 38 & 52 & 37 \\
Test offered at consultation & 42 & 57 & 39 \\
Telephone reminder & 27 & 48 & 42 \\
Postal reminder & 36 & 44 & - \\
Group meetings & 15 & 29 & - \\
Physician reminders & 34 & 50 & - \\
\hline
\end{tabular}

compliance by nearly $9 \%$. Another study showed no benefit from educational booklets ${ }^{39}$ and in one report uptake fell by $9 \% .{ }^{41}$ The content of such material is critical and may be more successful if cancer prevention is emphasised and reasons for non-compliance addressed. Problems have occurred with other screening programmes because of their educational material. In a survey of 174 authorities, $25 \%$ reported difficulties with the design of letters and leaflets in a cervical screening programme. Health education must adequately explain the results of tests and what is meant by pre-cancer. Notification of dysplasia on smears often causes women to assume they have cancer. A comparable problem could arise in colorectal cancer screening about the nature and consequences of polyps.

Remailing of non-responders can raise overall compliance by 5 to $10 \% .{ }^{16} \mathrm{~A}$ telephone reminder to non-compliers after 30 days significantly raised compliance from $27 \%$ to $37 \% .{ }^{42}$ In cervical cancer screening, telephoning non-responders also raised compliance by a third in women overdue for a smear.

Reminders to physicians on patients' screening status at routine consultations are effective. Computer generated lists of overdue screening tests increased compliance with faecal occult blood testing by $19 \%$. A similar study amongst physicians in an American hospital confirmed the beneficial effects of reminders and showed that monthly reports of compliance raised uptake. A combination of a computerised reminder and a questionnaire about screening status delivered to patients raised acceptance from $30 \%$ to $46 \%$. Methods which increase compliance are shown in Table III.

In Chicago, promotion of screening on the television's evening news was reinforced by radio and newspaper features. Of 54000 kits distributed, only $14000(26 \%)$ were completed. Similarly in Pennsylvania, an educational series on colorectal cancer was delivered nightly by a local television station. A total of 130000 tests were delivered as a result of the programmes and $53 \%$ returned.

Administrative problems encountered in cervical screening provide lessons for colorectal cancer programmes. Frequently invitations are sent to the wrong address or to women who have had smears of even a hysterectomy. These problems are largely due to patients failure to notify general practitioners of address changes and practices not informing family practitioner committees. In a study of non-attendance at mammography, $14 \%$ of alleged non-compliers had actually attended for screening. Other interventions used in cervical and breast screening including specific appointment times for screening, educational pamphlets at routine consultations, and tagging the case notes of non-compliers also have a place in colorectal screening.

\section{ACCEPTABILITY OF STOOL TESTING}

Non-compliance studies are hard because people who decline screening are reluctant to be interviewed and it can be difficult to elicit precise reasons and be confident they are valid. In Denmark where 1000 non-compliers were questioned, $37 \%$ did not give a specific reason $^{43}$ and in a British group, ${ }^{35} 40 \%$ were 'too busy' and 'didn't get round to it'. In a study of hospital employees reasons given were 'too lazy, couldn't be bothered, kept putting it off, forgot or mislaid slides'. Such apparent lethargy and lack of time may mask real fears about screening and cancer. In a questionnaire study, Macrae et al reported that refusers were more likely to rate tests as embarrassing, distasteful, worrisome, discomforting, or inconvenient than acceptors. ${ }^{44}$ Farrands et al ${ }^{35}$ found that $22 \%$ of non-compliers thought faecal testing unacceptable, although this was not investigated further. In a workplace programme ${ }^{45}$ a third of those who received a kit described it as unpleasant and $17 \%$ said the specimen was too difficult to collect. As less than $50 \%$ of people returned a questionnaire the number who held this view was probably higher. Finally, in a general practice based study, non-completers were seven times more likely to rate faecal occult blood testing as 'disgusting' than completers. ${ }^{46}$ Designing a more acceptable kit may increase compliance but is a difficult task. One system under evaluation involves dropping a card into the toilet and looking for a colour change. ${ }^{46}$ This relies on blood on the surface of the stool forming a film with which the test card reacts. It is preferred by patients because samples do not have to be collected. Unfortunately it is less sensitive than the Haemoccult test and problems may occur when patients read their own tests. In another test, participants wipe their anus after defecation and then develop the smear with a guiac/peroxide spray. ${ }^{46}$

The immediate barriers to completing a screening test seem to outweigh the possible long term benefits of screening in some noncompliers. This is true in cervical cancer screening where a major concern is that taking the smear will be painful and embarrassing. Similarly, in breast cancer screening many women are concerned about the clinic experience where over a third expressed negative feelings and a dislike of physical examination, doctors, and the presence of other women at the clinic.

THE CONCEPT OF ASYMPTOMATIC ILLNESS Concepts of asymptomatic illness and screening need to be promoted as the public are unaware of these. ${ }^{354345}$ Farrands et al found acceptors were more aware that cancer could be present before causing symptoms and could 
be diagnosed by medical tests. ${ }^{35}$ Acceptors were more likely to believe that asymptomatic cancer was curable. Similarly, Silman et al found that $64 \%$ of those who declined screening did so because of lack of symptoms, ${ }^{45}$ and in Denmark $^{43} 13 \%$ refused because they felt well. Similarly, in cervical screening attenders were more likely than non-attenders to believe that smears can reveal disease before symptoms and that early detection is beneficial. In mammography, many non-attenders thought screening unnecessary as they were well and that they should not waste professionals' time.

Other reported reasons for non-participation include intercurrent illness, advancing age, ${ }^{43}$ and fear of cancer. ${ }^{35} 45$ Klaaborg et al ${ }^{43}$ found that $32 \%$ of rejectors cited another illness or current medical treatment and $4 \%$ felt they were too old to benefit. In two British studies $^{3545}$ surprisingly few people directly voiced concerns about fear of cancer, although denial is probably important.

THE 'HEALTH BELIEF' MODEL

The 'health belief' model was developed to help understand why people participate in health related behaviours such as screening. Criteria include an individual's perceived susceptibility to disease and the severity of its consequences and motivations, and barriers and cues to enrolling in screening programmes. Macrae et $\mathrm{al}^{44}$ used the model to predict colon cancer screening behaviour. The main findings were that refusers thought they were less susceptible to colorectal cancer than acceptors, although the perceived severity of the disease was similar. In contrast to other work, ${ }^{46}$ acceptors and refusers had similar confidence in treatment efficacy, although, not surprisingly, barriers such as distaste of testing were pronounced in refusers. The New York group applied the 'health belief model to their population and found perceived susceptibility was similar in responders and nonresponders, although this population were self enrolled in a health programme. These noncompliers believed that colorectal cancer was a more severe illness and were less confident of treatment. Perceived seriousness of the illness was again a motivating factor in a Dutch study using the 'health belief' model. This model has also been used to investigate reasons for nonattendance at mammography. Attenders were more likely to feel vulnerable and be more concerned about breast cancer.

A thorough understanding of why people do not participate is essential if a high compliance is to be achieved. If mortality is reduced then publicity and education about screening must be more widespread. Education is needed to promote the concept of asymptomatic illness. Furthermore, identification of tests that patients find more acceptable is critical to the success of any screening programme.

\section{Criterion 5: Screening is cost effective}

COSTINGS FROM SCREENING TRIALS

A national screening programme will not be developed until there is a reliable estimate of its cost benefits. Currently, this is impossible as a reduction in mortality due to screening has not yet been shown. However, several studies have calculated the costs of a screening programme ${ }^{47}$ and compared these with the costs resources used to treat patients presenting with symptoms. In Nottingham, ${ }^{47} £ 5$ was spent per person screened and the cost per screen detected cancer was $£ 2700$. There would then be the extra cost of treating patients identified by screening, although ultimately some would become symptomatic and require treatment. Cost was more dependent on clinical variables such as test sensitivity and compliance than on staff and administrative resources. A similar sum was spent on investigations and treatment following a positive stool test as for a symptomatic patient. Although it is more expensive than a barium enema, colonoscopy is the investigation of choice as it has a greater sensitivity for polyps.

The cheapest method of screening was to mail kits from a hospital unit rather than asking individuals to collect them as this produces higher compliance. Screening older asymptomatic people is more cost effective as the incidence of disease is increased. The price per cancer detected at initial and the subsequent rescreen is similar, but rises considerably for the second rescreen at four years, as fewer people with an abnormality are found.

\section{COSTS CALCULATED FROM A MATHEMATICAL} MODEL AND POLYP REMOVAL

The mathematical model of screening constructed by Eddy ${ }^{26}$ has been used to cost colorectal cancer screening programmes. An annual faecal occult blood test and three yearly flexible sigmoidoscopy costs four times that of a yearly faecal occult blood test but is one and a half times better at reducing the risk of death. The most effective way to reduce mortality is a yearly occult blood test and full colonoscopy but this was eight times more expensive than just a three yearly sigmoidoscopy.

Screening should reduce the amount spent on treating colorectal cancer through earlier diagnosis and polyp removal. Allison and Feldman ${ }^{49}$ compared the resources spent over five years on treating 12 patients with screen detected carcinoma with what would be spent had they presented symptomatically. Diagnosing patients earlier cost $15 \%$ less over this period. Whynes et al ${ }^{50}$ calculated that 53 cancers would have been prevented by polypectomy in the Nottingham study and that this saving covered $20 \%$ of the costs of the programme. In a proposed trial of flexible sigmoidoscopy, Atkin et al $^{27}$ suggested the cost of preventing cancer is similar to that spent treating a symptomatic patient. Assuming 70\% compliance, the cost of screening and surveillance in the UK would be $£ 30$ million annually. This translates to $£ 5500$ per cancer prevented or $£ 8500$ per cancer death prevented. These figures need to be compared with the $£ 100$ million spent on inpatient care $(£ 4500$ per patient) for colorectal cancer in 
England and Wales. There will also be other costs of a screening programme including a public health education campaign to raise awareness. Understandably this has not been costed for colorectal cancer but would need to be extensive to increase participation.

Although faecal occult blood tests are relatively cheap (approximately $£ 1.20$ ), the cost of investigating a patient with a positive test is 200 times that of the stool kits. Therefore screening must minimise false positives and avoid investigating healthy people. In the USA, for every $1 \%$ increase in the false positive rate 570000 more people would need to be investigated if there was a national screening programme.

\section{COST COMPARISON WITH OTHER CANCER} SCREENING PROGRAMMES

The United Kingdom Breast Cancer Screening Programme was evaluated using QALY techniques (quality adjusted life year gained) and a figure of $£ 3304 / \mathrm{QALY}$ calculated at 1983-84 prices. An assessment of the cost of saving one life from cervical screening quoted a figure of $£ 30000 .^{51}$ This compares with a cost of $£ 2700$ to detect one colorectal neoplasm by stool testing ${ }^{47}$ and $£ 8500$ to prevent a death by flexible sigmoidoscopy. ${ }^{27}$

There are other hidden costs of a screening programme including the financing of a public health education programme. Public health education campaigns could be advertised on radio, television, or through educational leaflets. Television campaigns raise awareness, for example in an Australian programme for the early detection of melanoma. ${ }^{52}$ Naturally this approach has never been costed for colorectal cancer but would need to be extensive to raise awareness. Medicolegal considerations will occur if patients suffer because doctors fail to take appropriate action on receipt of positive screening tests. Unfortunately, this does happen, for example in Pennsylvania where $35 \%$ of participants with a positive faecal occult blood test had limited diagnostic investigations. Similarly, in cervical cancer screening, not all health authorities operated a fail safe system to ensure adequate follow up was instigated for women with positive smears. Screening centres and general practitioners must initiate appropriate investigation of all those with positive results to avoid medicolegal problems.

When mortality data are available a more accurate cost-benefit analysis can be calculated. Provisional cost estimates suggest the beneficial effects of finding earlier tumours and polyps may pay for a third of the service. Costs for screening and treatment seem of a similar order fulfilling an important screening principle.

\section{The future}

The evidence shows that colorectal cancer screening satisfies many of the criteria for screening programmes. The disease is common and can be diagnosed early in its natural history when treatment is easiest and prognosis best. Although faecal occult blood tests are cheap and non-invasive they lack sensitivity so the value of other tests such as sigmoidoscopy needs to be determined. The available evidence shows that the costs of a screening programme are of the same order of magnitude as the cost of treatment. The calculated cost is less than that required in breast and cervical screening programmes. Currently compliance with colorectal cancer screening is a major deterrent to government investment. To address this problem more research is needed on methods of delivery and reasons why people decline tests.

Our ultimate aim should be an effective national screening programme which will alleviate morbidity and mortality caused by colorectal cancer. While evaluating methods of screening is vital, equal emphasis must be placed on improved public understanding and acceptance of the process.

For this review, the principle references are included. A more extensive list of material used to compile this article is available from the authors.

1 Lochart-Mummery HE, Ritchie JK, Hawley PR. The results of surgical treatment for carcinoma of the rectum at St Mark's Hospital from 1948 to 1972. Br f Surg 1976; 63: $673-7$

2 Clarke DN, Jones PF, Needham CD. Outcome in colorectal carcinoma: seven year study of a population. $B M \mathcal{F} 1980$; $\mathrm{i}$ : $431-5$

3 Shinya $\mathrm{H}$, Wolff WI. Morphology, anatomic distribution and cancer potential of colonic polyps. An analysis of 7000 polyps endoscopically removed. Ann Surg 1979; 190: 679-83.

4 Muto T, Bussey HJR, Morson BC. The evolution of cancer of the colon and rectum. Cancer 1975; 36: 2251-70.

5 Winnawer SJ, Zauber AG, O'Brien MJ, Gottlieb LS, Sternberg SS, Stewart ET, et al. The national polyp study. Sternberg SS, Stewart ET, et al. The national polyp study. newly diagnosed polyps. Cancer 1992; 70: 1236-45.

6 Morson B. The polyp-cancer sequence in the large bowel. Proc Roy Soc Med 1974; 67: 451-7.

7 Stryker SJ, Wolff BG, Culp CE, Libbe SL, Ilstrup DM, MacCarty RL. Natural history of untreated colonic polyps. Gastroenterology 1987; 93: 1009-13.

8 Winnawer SJ, Zauber AG, Ho MN, et al. Prevention of colorectal cancer by colonoscopic polypectomy. $N$ Eng $\tilde{f}$ Med 1993; 329: 1977-81.

9 Atkin WS, Morson BC, Cuzick J. Long-term risk of colorectal cancer after excision of rectosigmoid adenomas. $N$ Eng $\mathcal{F}$ Med 1992; 326: 658-62.

10 Thomas WM, Pye G, Hardcastle JD, Chamberlain JO, Charnley RM. Role of dietary restriction in Haemoccult Charnley RM. Role of dietary restriction in Haemoccult

11 Griffith CDM, Turner DJ, Saunders JH. False negative results of Haemoccult test in colorectal cancer. BMF 1981; 283: 472.

12 Farrands PA, Hardcastle JD. Accuracy of occult blood tests over a six day period. Clin Oncol 1983; 9: 217-25.

3 McDonald C, Goulston K. Colorectal test for occult blood. Med F A ust 1984; 140: 183.

14 Mandel JS, Bond JH, Bradley M, Snover DC, Church TR, Williams S, et al. Sensitivity, specificity and positive predictivity of the hemoccult test in screening for colorectal cancers. Gastroenterology 1989; 97: 597-600.

15 Hardcastle JD, Chamberlain J, Sheffield J. Randomised controlled trial of faecal occult blood screening for colorectal cancer. Results for first 107349 subjects. Lancet rectal cancer. Resur i: $1160-4$.

16 Thomas WM, Hardcastle JD. An update on the Nottingham trial of faecal occult blood screening for colorectal carcinoma. In: Miller AB, Chamberlain J, Day NE, Hakama M, Prorok PC, eds. Cancer screening. Cambridge: Cambridge University Press, 1991: 106-15.

17 Mandel JS, Bond JH, Church TR, Snover DC, Bradley GM, Schuman LS, et al. Reducing mortality from colorectal cancer by screening for fecal occult blood. $N$ Eng $\mathcal{F}$ Med 1993; 328: 1365-71.

18 Flehinger BJ, Herbert E, Winnawer SJ, Miller DG. Screening for colorectal cancer with fecal occult blood test and sigmoidoscopy: Preliminary report of the colon project of Memorial Sloan-Kettering Cancer Center and PMI-Strang Clinic. In: Chamberlain J, Miller AB, eds. Screening for gastrointestinal cancer. Toronto: Hans Huber Publishers, 1987: 9-16.

9 Winnawer SJ, Schottenfeld D, Flehinger BJ. Colorectal cancer screening. F Nat Cancer Inst 1991; 83: 243-53.

20 Kronborg O, Fenger C, Olsen J. Interim report on a randomised trial of screening for colorectal cancer with Hemoccult II. In: Miller AB, Chamberlain J, Day NE, Hakama M, Prorok PC, eds. Cancer screening. Cambridge: Cambridge University Press, 1991: 126-30. 
21 Kewenter J, Asztely M, Engaras B, Haglind E, Svanvik J, Ahren C. A randomised trial of faecal occult blood testing for early detection of colorectal cancer. Results of screening and rescreening of 51325 subjects. In: Miller AB Chamberlain J, Day NE, Hakama M, Prorok PC, eds. Cancer screening. Cambridge: Cambridge University Press, 1991: 116-25

22 Wahrendorf J, Robra BP, Wiebelt $\mathrm{H}$, Oberhausen $\mathrm{R}$ Weiland M, Dhom G. Effectiveness of colorectal cancer screening: results from a population-based case-control evaluation in Saarland, Germany. European fournal of Cancer Prevention 1993; 2: 221-7.

23 Anderson GH, Boyes DA, Benedet JL, Le Riche JC, Matisic $\mathrm{JP}$, Sven KC, et al. Organisation and results of the cervical cytology screening programme in British Columbia, 1955-85. BMF 1988; 296: 975-8.

24 Peeters PHM, Verbeek ALM, Hendriks JHCL, Holland R Mravunac $M$, Vooijs GP. The occurrence of interval Mravunac M, Vooijs GP. The occurrence of interval cancers in the Nijmegen
Cancer 1989; 59: 929-32.

25 Paterson MEL, Peel KR, Joslin CAF. Cervical smear histories of 500 women with invasive cancer in Yorkshire. BMF 1984; 289: 896-989.

26 Eddy DM. Screening for colorectal cancer. Ann Intern Med 1990; 113: 373-84

27 Atkin WS, Cuzick J, Northover JMA, Whynes DK Prevention of colorectal cancer by once-only flexible sigmoidoscopy. Lancet 1993; 341: 736-40.

28 Gilbertsen VA, Nelms JM. The prevention of invasive cancer of the rectum. Cancer 1978; 41: 1137-9.

29 Friedman GM, Collen MF, Fireman BH Multiphasic health checkup evaluation: a 16 year follow-up. $¥$ Chronic Dis 1986; 39: 453-63.

30 Selby JV, Friedman GD, Queensbury CP, Weiss NS. A casecontrol study of screening sigmoidoscopy and mortality from colorectal cancer. New Eng $\mathcal{F}$ Med 1992; 326: 653-7.

31 Newcomb PA, Norfleet RG, Storer BE, Surawicz S, Marcus PM. Screening sigmoidoscopy and colorectal cancer mortality. $\mathcal{F}$ Natl Cancer Inst 1992; 84: 1572-5.

32 Hertz REL, Deddish MR, Day E. Value of periodic examinations in detecting cancer of the rectum and colon. Postgrad Med f 1960; 27: 290-4.

33 Foley DP, Dunne P, O'Brien M, Crowe J, O'Callaghan TW, Lennon JR. Left sided colonoscopy as screening procedure for colorectal neoplasia in asymptomatic volunprocedure for colorectal neoplasia in as

34 Hoff G, Vatn M, Gjone E, Larsen S, Sauar J. Epidemiology of polyps in the rectum and sigmoid colon. Design of a population screening study. Scand $\mathcal{F}$ Gastroenterol 1985; 20: 351-5.

35 Farrands PA, Hardcastle JD, Chamberlain J, Moss S. Factors affecting compliance with screening for colorecta cancer. Community Medicine 1984; 6: 12-9.

36 Dent O, Goulston K. Socio-demographic correlates of intended acceptance of colorectal cancer screening. Aust NZ F Med 1980; 10: 115 .

37 Hardcastle JD, Farrands PA, Balfour, Chamberlain J, Amar
SS, Sheldon MG. Controlled trial of faecal occult blood testing in the detection of colorectal cancer. Lancet 1983; ii: $1-4$.

38 Hobbs FDR, Cherry RC, Fielding JWL, Pike L, Holder R. Acceptability of opportunistic screening for occult gastrointestinal blood loss. $B M F$ 1992; 304: 483-6.

39 Nichols S, Koch E, Lallemand RC, Heald RJ, Izzard L, Machin D, et al. Randomised trial of compliance with screening for colorectal cancer. $B M \mathcal{F}$ 1986; 293: 107-10.

40 Mant D, Fuller A, Northover J. Patient compliance with colorectal cancer screening in general practice. $\mathrm{Br} f \mathrm{Gen}$ Pract 1992; 42: 18-20.

41 Pye G, Christie M, Chamberlain JO, Moss SM, Hardcastle JD. A comparison of methods for increasing compliance within a general practitioner based screening project for colorectal cancer and the effect on practitioner workload. colorectal cancer and the effect on practitioner work

42 Myers RE, Ross ER, Wolf TA, Balshern A, Jepson C, Milner L. Behavioral interventions to increase adherence in colorectal cancer screening. Med Care 1991; 29: 1039-50.

43 Klaaborg K, Stahl Madsen M, Sondergaard O, Kronborg O. Participation in mass screening for colorectal cancer with fecal occult blood tests. Scand 7 Gastroenterol 1986; 21: $1180-4$.

44 Macrae FA, Hill DJ, St John JB, Ambikapathy A, Garner JF. Predicting colon cancer screening behaviour from health beliefs. Prev Med 1984; 13: 115-26.

45 Silman A, Mitchell P. Attitudes of non-participants in an occupational based programme of screening for colorectal cancer. Community Medicine 1984; 6: 8-11.

46 Hunter W, Farmer A, Mant D, Verne J, Northover J, Fitzpatrick R. The effect of self-administered faecal occult blood tests on compliance with screening for colorectal cancer: results of a survey of those invited. Fam Pract 1991; 8: 367-72.

47 Walker A, Whynes DK, Chamberlain JO, Hardcastle JD The cost of screening for colorectal cancer. 7 Epidemiol and Community Health 1991; 45: 220-4.

48 Walker AR, Whynes DK, Chamberlain JO, Hardcastle JD. The hospital costs of diagnostic procedures for colorectal cancer. F Clin Epidemiol 1991; 44: 907-14.

49 Allison JE, Feldman R Cost benefits of hemoccult screening for colorectal carcinoma. Dig Dis Sci 1985; 30: $860-5$

50 Whynes DK, Walker AR, Hardcastle JD. Cost savings in mass population screening for colorectal cancer resulting from the early detection and excision of adenomas. Health Economics 1992; 1: 53-60.

51 Day NE, Miller AB, Parkin DM. How much can the NHS afford to spend to save a life or avoid a severe disability? Lancet 1985; i: 280-1.

52 Theobald T, Marks R, Hill D, Dorevitch A. 'Goodbye sunshine': effect of a television programme about melanoma on beliefs, behavior and melanoma thickness. $y$ Am Acad Dermatol 1991; 25: 717-23. 